\title{
REVISTA MARINGÁ ENSINA: ASSUNTOS EDUCACIONAIS EM CIRCULAÇÃO NA SEÇÃO ENTREVISTA - 2006 A 2011
}

\author{
Elaine Rodrigues \\ Ednéia Regina Rossi \\ Andréia Cristina Ernega \\ Edilene Cunha Martinez \\ Universidade Estadual de Maringá - UEM
}

\section{RESUMO}

Escolhemos a Revista Maringá ensina distribuída trimestralmente pela Secretaria de Educação de Maringá, como fonte e objeto para nossa pesquisa, considerando que os periódicos ligados aos professores podem ser entendidos como núcleos de (in) formação, pois mostram maneiras de produzir e difundir discursos. $\mathrm{O}$ objetivo geral é identificar o que a Revista Maringá Ensina, por meio da seção Entrevista, prioriza como temas relevantes para discussão e para ampliação dos conhecimentos que fundamentam a prática dos agentes educacionais maringaenses. Metodologicamente nos propomos a realizar um trabalho de caráter qualitativo, pretendemos descrever e interpretar, priorizando forma e conteúdo do periódico. A temporalidade recortada para estudo está circunscrita aos anos de 2006 a 2011. Cabe destacar que na investigação qualitativa a fonte é considerada relevante, mas o investigador/problematizador é o instrumento principal.

Palavras chave: História da Educação; Imprensa pedagógica; Revista Maringá Ensina.

\section{REVISTA MARINGÁ ENSINA: EDUCATIONAL ISSUES OUTSTANDING IN SECTION INTERVIEW - 2006 TO 2011}

\begin{abstract}
We selected Revista Maringá Ensina, a magazine quarterly issued by the Secretariat of Education of Maringá as fountain and goal of our research considering that publications related to educators can be understood as hubs of (in) formation, since they show ways of producing and spreading speeches. The general target is to identify what Revista Maringá Ensina by means of what the interview section takes as a priority for the discussion and enlargement of what may be considered the basis of knowledge of educational agents in Maringá, Methodologically, our purpose is a work of qualitative nature where the intention is to describe and interpret emphasizing shape and content of the periodical. Temporariness is focused between 2006 and 2011. Qualitative investigation is an outstanding source where the investigator is the main character.

Keywords: History of Education; Pedagogical Press; Maringá Ensina Magazine.
\end{abstract}

\section{Revista Maringá Ensina: Seu Uso Como Fonte}

$\mathrm{O}$ uso de jornais e revistas como fonte na pesquisa historiográfica teve seu prestígio validado há mais tempo na preferência dos pesquisadores da História. No caso da História da Educação muitos têm se dedicado ao estudo dos impressos que circulam na comunidade educacional e mais especificamente junto ao público escolar. O trabalho com a Imprensa Pedagógica, seja como fonte ou objeto de estudo, tem se tornado cada vez mais frequente e a análise de seus editoriais, cartas ao leitor, entrevistas e demais seções presentes no impresso são considerados fundamentais ao enriquecimento da História da Educação. 
O trabalho com Impressos Pedagógicos não é propriamente uma novidade entre os historiadores da educação, há que se destacar o aumento progressivo de artigos resultantes de pesquisas históricas desenvolvidas no campo da educação, que a partir de 1990, elegem a Imprensa Pedagógica como fonte. Citamos, somente a titulo de exemplo, Bastos (1997), Biccas (2008), Martinez (2009), Oliveira (2011), Silva (2012), Rodrigues (2010).

A produção da historiográfica afeta ao campo da história que toma como base a imprensa é registrada de modo mais evidente a partir das décadas de 1960 e 1970. A presença das revistas e jornais como fonte para o trabalho historiográfico é parte das mudanças que se processaram no que tange à compreensão do que seria um documento (LE GOFF, 2003; BLOCH, 2001) e do que pode ser considerado como fonte para o trabalho do historiador e também do historiador da educação.

A imprensa pedagógica anuncia discursos e expressões de diferentes protagonistas, possibilitando diálogos que evidenciam características de determinados grupos sociais o que permite, por parte do historiador da educação, realizar a tarefa de questionar e destacar diferentes formas de apropriação (CHARTIER, 1990; CERTEAU, 2006) evidenciadas em meio aos acontecimentos ou ainda acerca da própria criação destes.

Entre as décadas de 1960 e 1970, o uso da imprensa pedagógica como fonte para a escrita da história foi tomada com desconfiança e até desacreditada. Conforme Capelato (1988, p.13) o que antes foi considerado fonte suspeita e de pouca importância, hoje é reconhecido como material valioso para o estudo de um período, um recorte no tempo. A imprensa pedagógica registra, comenta, participa da história, possibilitando ao pesquisador problematizá-la afim de que haja uma organização e sistematização destes vestígios para a confecção da história e ou da história da educação.

Nas palavras de Sodré (1966), registra-se a história da imprensa, ressaltando-a em momentos políticos importantes do Brasil. O seu trabalho sobre imprensa abrange os períodos: regencial, imperial, republicano e contemporâneo. Mas é no período da independência que seu livro se expressa de forma mais rica. Bahia ${ }^{1}$ (1972) é um teórico do jornalismo. Capelato (1988) problematiza a relação entre a História e a imprensa, registrando a importância do uso do Jornal como fonte para a historiografia. Os estudos sobre Imprensa Pedagógica como fonte ganharam visibilidade, sobretudo, depois dos anos de 1990, haja vista o número de revistas, jornais e outros periódicos, dedicados a comunidade educacional, publicados com regularidade.

A Imprensa Pedagógica como fonte é significativa, dentre outras possibilidades, para se conhecer a organização pretendida para o universo escolar. Evidencia as diretrizes oficiais que a escola recebe e necessita atender e ao mesmo tempo permite a identificação de outros fatores integrantes da construção do que denominamos espaço escolar, os pontos de confluência que compõem as diversas facetas registradas no impresso. Com base no que está registrado no impresso, pode-se, ampliar a compreensão que se tem construída acerca do universo escolar, adentrando o ensino e suas características por perspectivas outras, diferentes daquelas consideradas consolidadas. Para Bastos (1997, p.49), a análise do impresso pedagógico - jornais, boletins, revistas, possibilita avaliar a política das organizações, as preocupações sociais, os antagonismos e filiações ideológicas e as práticas educativas.

A imprensa é um meio para apreender a multiplicidade do campo educacional, revela múltiplas facetas dos processos educativos. "A imprensa constitui uma das melhores ilustrações da extraordinária diversidade que atravessa o campo educativo" (NÓVOA, 1997, p.12-13). A imprensa pedagógica com fonte, afirmam Lopes e Galvão (2001, 87), permite especificar as particularidades de uma dada realidade educacional em seu tempo e 
lugar tornado visíveis os desdobramentos que ocorrem no meio educativo, em acordo com os interesses dos envolvidos.

A Imprensa Pedagógica tem para Nóvoa (1997) poder revelador sobre a História da Educação de uma época. Concordamos com ele, porque, nos impressos, no jornal aparecem questões relevantes, para o campo educacional, que perpassaram a época em que estão em circulação. Esses periódicos, de forma geral, objetivam enriquecer as práticas educacionais do dia-a-dia escolar, informando sobre os programas oficiais, discutindo problemas educacionais, condutas e posicionamentos dos professores em sala de aula.

A Imprensa Pedagógica pede que a tomemos em seus princípios, aquela que veicula interesse de uma pessoa, uma instituição ou um grupo de pessoas com o objetivo de que sua mensagem seja incorporada. A Imprensa Pedagógica não divulga as informações de forma imparcial, neutra, ao contrário, divulga aspirações, concepções políticas, ideológicas, apresenta necessidades e objetivos específicos do grupo que propõem sua editoração, publicação.

Ao trabalho do historiador da educação, advertem Lopes e Galvão (2001), não basta investigar o processo de transformação e organização da escola ao longo do tempo. Assim como não é suficiente estudar o que pensam e propunham "educadores ilustres" e nem a construção de conhecimentos históricos que se baseia apenas em documentação "institucionalizada", representação oficial. É enriquecedor ao campo educacional fazer uso de fontes que possibilitem acesso a múltiplas formas de representação do objeto que se pretende estudar.

\section{Breve Histórico da Revista Maringá Ensina}

Tivemos acesso às revistas no Centro Municipal de Educação Infantil, Núcleo Social de Maringá - Paraná. O material estava arquivado em um armário, numa sala sem identificação, a qual não é utilizada, havia várias revistas da mesma edição, porém não todos os números o que nos levou a contatar a Secretaria de Educação do Município de Maringá (SEDUC) que forneceu os exemplares que faltavam. Ao todo são 17 revistas, entre os números 3 a 20 que abrangem o período temporal de 2006 a 2011, o que se justifica em razão do espaço-tempo de circulação do periódico.

Uma observação, mais cuidadosa, das fontes nos permitiu decidir trabalhar com a seção - Entrevista. Esta seção apresenta regularidade, permanecendo durante todos os anos de publicação, o que nos possibilita uma visão mais abrangente do material. A leitura, mesmo inicial, instigou-nos a perguntar: O que a Revista Maringá Ensina, uma publicação da Secretaria Municipal de Educação, por meio da seção Entrevista, prioriza como temas relevantes para discussão e para ampliação dos conhecimentos que fundamentam a prática dos agentes educacionais maringaenses? Frente a esse questionamento optamos por descrever, priorizando forma e conteúdo, a seção Entrevista, que compõe a Revista Maringá Ensina no período de 2006 a 2011.

A Revista Maringá Ensina é elaborada pela Secretaria Municipal de Educação de Maringá (SEDUC), com o objetivo de subsidiar a formação continuada e a prática pedagógica dos profissionais da educação da rede municipal de ensino. É distribuída trimestralmente a todos os professores e educadores dos Centros Municipais de Educação Infantil (C.M.E. Is) e Escolas Municipais do Município, bem como bibliotecas públicas e universitárias. 
Em um espaço destinado às cartas enviadas pelo leitor, seção opinião, identificamos que pessoas de outros municípios ${ }^{2}$ da região enviam suas opiniões, isso nos mostra que, mesmo as revista sendo distribuídas em Maringá, profissionais de outros municípios a utilizam como amparo a prática educacional. Destacamos que o conteúdo das cartas manifesta respeito e aceitação do trabalho divulgado pela revista.

Desde a década de 1970, foram lançadas em Maringá quatro principais revistas ${ }^{3}$, Aqui com a primeira edição em dezembro de 1979, Tradição que teve a primeira edição lançada em 1981, Pois É lançada em 1986 e a Maringá Ensina, fonte e objeto deste artigo, publicada desde 2006 até hoje.

A Revista Maringá Ensina, de caráter pedagógico, apresenta como principal objetivo publicar reportagens sobre o ensino de Maringá, destacando informações de projetos e trabalhos pedagógicos desenvolvidos nas escolas e centros da rede municipal, traz publicações de artigos e pesquisas desenvolvidas por profissionais de diversas áreas relacionadas com a educação. Segundo seus idealizados, a "Revista Maringá Ensina é um meio de comunicação que vai ligar o profissional da educação, o aluno e a comunidade" (MARINGÁ, 2006, p.4).

[...] Como Maringá não espera, Maringá ensina, nossa revista visa estreitar ainda mais os conceitos, conteúdos, planos e projetos que valorizam e capacita você, educador, que é o principal mediador entre passado, presente e futuro. [...] a educação é fator determinante para $o$ progresso e crescimento de Maringá, e sob essa ótica vista como o único meio de transformar o mundo em um lugar melhor para se viver [...] o norte do periódico é buscar informações e divulgá-las a fim de elevar a educação no nível máximo que ela merece. Por essa razão a Revista vem repleta de conhecimentos e cidadania. (MARINGÁ, 2007c, p.4)

Pontuamos que a Revista Maringá Ensina é um meio escolhido pela Secretaria de Educação para complementar a formação dos educadores da rede municipal, exercendo, portanto, a função de núcleo de (in) formação.

\section{Características Gerais da Revista Maringá Ensina}

Tomada como fonte a Revista Maringá Ensina, produzida e distribuída pela Secretaria Municipal de Educação, pode ser assim caracterizada: foram publicadas, no período de 2006 a 2001, 20 edições, destas selecionamos 17 revistas a partir do número 3, no qual se inaugura a seção 'entrevista' até a sua última edição que foi à público em 2011.

A revista Maringá Ensina foi criada no governo do Prefeito Silvio Barros, e este se manteve como Prefeito, até a última edição pesquisada, como mostra o quadro 1:

\begin{tabular}{|l|l|l|l|l|}
\hline $\begin{array}{l}\text { Número da } \\
\text { Revista }\end{array}$ & Data de Publicação & Prefeito & $\begin{array}{l}\text { Número de } \\
\text { Páginas }\end{array}$ & Tiragem \\
\hline 03 & Ago./set./out. 2006, ano1 & Silvio Magalhães Barros & 60 & Não informado \\
\hline 04 & Nov./dez. 2006, ano 1 & Silvio Magalhães Barros & 60 & Não informado \\
\hline 05 & Fev./mar./abril. 2007, ano 2 & Silvio Magalhães Barros & 68 & 8.000 \\
\hline 06 & Maio/jun./jul. 2007, ano 2 & Silvio Magalhães Barros & 56 & 5.000 \\
\hline 07 & Nov./dez.2007/jan. 2008, ano 2 & Silvio Magalhães Barros & 56 & 5.000 \\
\hline 08 & Abril/maio/jun. 2008, ano 3 & Silvio Magalhães Barros & 56 & 5.000 \\
\hline 09 & Ago./set./out. 2008, ano 3 & Silvio Magalhães Barros & 56 & 3.615 \\
\hline 10 & Fev./mar./abril. 2009, ano 4 & Silvio Magalhães Barros & 56 & 5.000 \\
\hline 11 & Maio/jun./jul. 2009, ano 4 & Silvio Magalhães Barros & 56 & 5.000 \\
\hline
\end{tabular}




\begin{tabular}{|l|l|l|l|l|}
\hline 12 & Jul./ago./set. 2009, ano 4 & Silvio Magalhães Barros & 56 & Não informado \\
\hline 13 & Nov./dez.2009 jan.2010, ano 4 & Silvio Magalhães Barros & 56 & 5.000 \\
\hline 14 & Fev./mar./abril 2010, ano 5 & Silvio Magalhães Barros & 56 & Não informado \\
\hline 15 & Maio/jun./jul. 2010, ano 5 & Silvio Magalhães Barros & 56 & Não informado \\
\hline 16 & Ago./set./out.2010, ano 5 & Silvio Magalhães Barros & 56 & Não informado \\
\hline 17 & Nov./dez.2010 jan.2011, ano 5 & Silvio Magalhães Barros & 56 & Não informado \\
\hline 18 & Fev./mar./abril 2011, ano 5 & Silvio Magalhães Barros & 56 & Não informado \\
\hline 19 & Maio/jun./jul.2011, ano 5 & Silvio Magalhães Barros & 56 & Não informado \\
\hline 20 & Ago./set./out.2011, ano 5 & Silvio Magalhães Barros & 56 & Não informado \\
\hline
\end{tabular}

Quadro 1 - Números da Revista Maringá Ensina

Fonte: Revista Maringá Ensina - Nº3 a 20 (organização das autoras)

Esse periódico assemelha-se com a estrutura de outros impressos dessa categoria. Percebemos nas capas e contracapas um material com textura um pouco mais grossa, comparada às demais páginas que a compõem. Seu formato é de aproximadamente 27,5 centímetros de cumprimento por aproximadamente 20,5 de largura. Sendo de fácil manuseio, com as impressões de textos na cor preta e boa definição de imagens nas quais aparecem fotos e gravuras. As capas são bastante coloridas e chamativas, observamos que em todas as edições as capas são fotos, de alunos da rede municipal, em que essas ilustrações têm a preocupação de registrar, na maioria, o tema central proposto para a edição, na página número "4" de cada revista há uma nota chamando a atenção do leitor para a capa da edição.

As imagens e os demais elementos que compõem a revista possuem intencionalidade. Chartier (1991) afirma que as formas produzem sentido à medida que modificam o objeto tipográfico que subjaz à leitura, modificando-se, assim, o significado que o leitor atribui a essa leitura.

Ao "ilustrar" o tema principal nas capas, a secretaria tinha como objetivo imprimir certa interpretação sobre os temas que seriam, naquela edição, abordados. O quadro 2, nos mostra quais os temas principais das edições:

\begin{tabular}{|l|l|}
\hline $\begin{array}{l}\text { Número } \\
\text { da } \\
\text { Revista }\end{array}$ & Tema \\
\hline 03 & Emoção x Risco para alunos da Rede Municipal de Ensino. \\
\hline 04 & Educção de jovens e Adultos (EJA). \\
\hline 05 & Especial de Aniversário de 1 ano de circulação da Revista Maringá ensina. \\
\hline 06 & Meio Ambiente. \\
\hline 07 & Festival: "No mundo encantado da Arte". \\
\hline 08 & Ensina fundamental de 9 anos. \\
\hline 09 & Diversidade. \\
\hline 10 & Oito jeitos de mudar o mundo. \\
\hline 11 & Maringá, 62 anos de desenvolvimento e qualidade de vida. \\
\hline 12 & A educação infantil e suas peculiaridades. \\
\hline 13 & A educação no ensino fundamental: Uma história em processo contínuo. \\
\hline 14 & A escola em tempo integral. \\
\hline 15 & A elaboração de conceitos científicos. \\
\hline 16 & $\begin{array}{l}\text { Educação infantil/crianças menores de sete anos, aprendizagem da linguagem escrita e } \\
\text { o ensino fundamental de nove anos. }\end{array}$ \\
\hline 17 & IDEB - Maringá atinge meta prevista pelo MEC para 2015. \\
\hline 18 & Bullying. \\
\hline 19 & Maringá, 64 anos. \\
\hline 20 & O ensino da Matemática por meio da resolução de problemas. \\
\hline
\end{tabular}

Quadro 2 - Temas principais de cada edição

Fonte: Revista Maringá Ensina n ${ }^{\circ} 03$ a 20 (organização das autoras) 
Os temas centrais são variáveis a cada edição, não são direcionados, exclusivamente, a nenhum nível de ensino, procuram sim, abranger todas as modalidades de ensino, destinada à rede municipal ${ }^{4}$. As temáticas utilizadas como âncora, não limitam a edição, são apenas um guia desta. Assim todas as revistas abordam também outros conteúdos, apresentados em várias seções, denominadas Mural, nas quais são publicados as atividades e eventos desenvolvidos pela Secretaria de educação. Há, ainda, a seção, O que rola na rede, por meio da qual são publicadas as experiências pedagógicas produzidas no interior das unidades escolares da rede municipal de ensino.

Na página número 04 há uma listagem - Expediente - com os nomes dos sujeitos que trabalharam na composição da revista. Nesta é especificado o nome dos colaboradores que enviaram artigos e matérias para publicação, bem como os principais sujeitos que participaram diretamente de sua elaboração. Descrevemos no quadro 3 o nome dos responsáveis pelas edições.

\begin{tabular}{|l|l|l|}
\hline Número Revista & $\begin{array}{l}\text { Secretária } \\
\text { Municipal } \\
\text { educação }\end{array} \quad \begin{array}{l}\text { (o) } \\
\text { da }\end{array}$ & Formação \\
\hline $03-04$ & $\begin{array}{l}\text { Norma Deffune } \\
\text { Leandro }\end{array}$ & Não encontrada \\
\hline $05-09$ & $\begin{array}{l}\text { Manoel Gomes } \\
\text { Márcia do Roccio } \\
\text { Socreppa }\end{array}$ & $\begin{array}{l}\text { Tem formação em Letras; já foi secretário da Educação em Sarandi e } \\
\text { diretor de diversos estabelecimentos educacionais. }\end{array}$ \\
\hline $10-17$ & $\begin{array}{l}\text { Tedro Brambilla } \\
\text { Professora Edith Dias em pedagogia - PUC Curitiba } \\
\text { de Carvalho }\end{array}$ & $\begin{array}{l}\text { Faro encontrada em Pedagogia pela Universidade Estadual de Maringá (UEM), } \\
\text { com pós-graduação em Educação, integrou o quadro docente da Rede } \\
\text { Estadual. }\end{array}$ \\
\hline $18-19$ & \multicolumn{2}{|l}{} \\
\hline
\end{tabular}

Quadro 3 - Organizadores do impresso

Fonte: Revista Maringá Ensina n ${ }^{\circ} 03$ a 20 (organização das autoras)

A materialidade da Revista Maringá Ensina, manteve-se inalterada durante as trocas de Secretários de Educação, não havendo interferências em sua publicação. No quadro 4, destacamos os responsáveis pela organização das edições, desde a escolha de temas a serem publicados, até a organização final da revista.

\begin{tabular}{|l|l|}
\hline $\begin{array}{l}\text { Número } \\
\text { da Revista }\end{array}$ & $\begin{array}{l}\text { Coordenação de edição/conselho } \\
\text { Editorial }\end{array}$ \\
\hline 03 & Flávia Inessa Leandro; Francisco Maravieski; Henri Jean Viana; Nícia Pelegrini de Almeida; \\
\hline $04-05$ & $\begin{array}{l}\text { Adriana de Oliveira Chaves Palmieri; Flávia Inessa Leandro; Francisco Maravieski; Henri Jean Viana; } \\
\text { Nícia Pelegrini de Almeida. }\end{array}$ \\
\hline $06-09$ & $\begin{array}{l}\text { Adriana de Oliveira Chaves Palmieri; Diniz Neto; Erick Rodrigo Bucioli; Flávia Inessa Leandro; Francisco } \\
\text { Maravieski; Ivete Gruchovisk. }\end{array}$ \\
\hline $10-12$ & $\begin{array}{l}\text { Diniz Neto; Erick Rodrigo Bucioli; Flávia Inessa Leandro; Francisco Maravieski; Ivete Gruchovisk; Maria } \\
\text { da Penha. }\end{array}$ \\
\hline $13-14$ & $\begin{array}{l}\text { Débora Gomes; Diniz Neto; Erick Rodrigo Bucioli; Flávia Inessa Leandro; Francisco Maravieski; Janaina } \\
\text { C. Batista; Lia Marli Adams; Maria da Penha. }\end{array}$ \\
\hline 15 & $\begin{array}{l}\text { Débora Gomes; Eliana Moreira Amaral de Souza; Erick Rodrigo Bucioli; Flávia Inessa Leandro; Francisco } \\
\text { Maravieski; Janaina C. Batista; Lia Marli Adams; Maria da Penha; Marlene de Lima Santos; Priscila dos } \\
\text { Santos; Salete Monteiro Guedes; Sandra Regina A. dos santos. }\end{array}$ \\
\hline $16-20$ & $\begin{array}{l}\text { Debora Gomes; Eliana Moreira; Amaral de Souza; } \\
\text { Gonçalves Braz; Francisco Maravieski; Flávia Inessa Leandro; Janaina Candido Batista; Lia Marli Adams; } \\
\text { Maria da Penha; Marlene de Lima Santos; Paulo Roberto Gonçalves; Salete Monteiro Guedes; Sandra } \\
\text { Regina A. dos Santos. }\end{array}$ \\
\hline
\end{tabular}

Quadro 4 - Organizadores gráficos do impresso

Fonte: Revista Maringá Ensina nº 03 a 20 (organização das autoras) 
Selecionamos, nos quadros 3 e 4, os sujeitos que participaram da organização geral e da organização gráfica da Revista Maringá Ensina, destacamos que apenas dois deles são formados em pedagogia. Interessante refletir sobre isso, afinal, o impresso é pedagógico.

\section{Conteúdo em Circulação na Seção Entrevista: O Que Se Quer Comunicar?}

A seleção da seção Entrevista aconteceu em razão de que, ao manipularmos a Revista Maringá ensina, notamos que esta apresenta regularidade, permanecendo, desde a revista de número 3 até a revista de número 20, o que nos possibilitou uma visão mais abrangente do material que dispúnhamos para o trabalho.

Pontuamos no quadro 5 os números das edições, os nomes dos entrevistadores; os entrevistados e os temas das entrevistas. Preocupados em compreender melhor o universo de composição do periódico em estudo, efetuamos pesquisas em locais como a plataforma Lattes, mas não foi possível encontrar nenhuma informação que vinculasse os entrevistadores ao mundo educacional, isso nos fez hipoteticamente inferir, provavelmente sejam funcionários da Secretaria Municipal de Educação. Observe-se:

\begin{tabular}{|c|c|c|c|}
\hline $\begin{array}{l}\text { Número da } \\
\text { revista }\end{array}$ & Entrevistador & Entrevistado & Tema das entrevistas \\
\hline 03 & Não informado & Içami Tiba & $\begin{array}{l}\text { Aborda assuntos sobre adolescentes; relação pais e } \\
\text { filhos; carreira profissional do professor; educação e } \\
\text { valores, }\end{array}$ \\
\hline 04 & $\begin{array}{l}\text { Adriana Palmieri e } \\
\text { Flávia Leandro }\end{array}$ & Gabriel Chalita & Aponta discussões acerca da educação do país. \\
\hline 05 & $\begin{array}{l}\text { Adriana Palmieri e } \\
\text { Flávia Leandro }\end{array}$ & Viviane Senna & $\begin{array}{l}\text { Aborda importância do investimento na educação da } \\
\text { criança e do adolescente. }\end{array}$ \\
\hline 06 & $\begin{array}{lr}\text { Adriana } & \text { Palmieri e } \\
\text { Flávia } & \text { Inessa } \\
\text { Leandro } & \\
\end{array}$ & $\begin{array}{l}\text { Antonio Ermínio de } \\
\text { Moraes }\end{array}$ & $\begin{array}{l}\text { Fala sobre educação, responsabilidade social e o meio } \\
\text { ambiente. }\end{array}$ \\
\hline 07 & $\begin{array}{lr}\text { Adriana } & \text { Palmieri e } \\
\text { Flávia } & \text { Inessa } \\
\text { Leandro } & \end{array}$ & $\begin{array}{l}\text { Tenente-coronel } \\
\text { Rita Aparecida de } \\
\text { Oliveira }\end{array}$ & $\begin{array}{l}\text { Aborda sobre o importante papel da escola e da família } \\
\text { para garantir a educação e a boa formação do jovem na } \\
\text { sociedade. }\end{array}$ \\
\hline 08 & $\begin{array}{lr}\text { Adriana } & \text { Palmieri e } \\
\text { Flávia } & \text { Inessa } \\
\text { Leandro } & \\
\end{array}$ & $\begin{array}{ll}\text { Maria } & \text { do } \text { Pilar } \\
\text { Lacerda } & \text { Almeida e } \\
\text { Silva } & \\
\end{array}$ & $\begin{array}{l}\text { Fala sobre o conjunto de ações e metas do Plano de } \\
\text { Desenvolvimento da Educação previsto pelo MEC. }\end{array}$ \\
\hline 09 & $\begin{array}{lr}\text { Adriana } & \text { Palmieri e } \\
\text { Flávia } & \text { Inessa } \\
\text { Leandro } & \end{array}$ & Gabriel Perissé & $\begin{array}{l}\text { Desperta reflexões sobre a aprendizagem e a função do } \\
\text { educador nesse processo }\end{array}$ \\
\hline 10 & $\begin{array}{lr}\text { Adriana } & \text { Palmieri e } \\
\text { Flávia } & \text { Inessa } \\
\text { Leandro } & \end{array}$ & José Pacheco & $\begin{array}{l}\text { Fala sobre a educação brasileira, sobre o papel do } \\
\text { educador e sobre os processos de aprendizagem na } \\
\text { construção de uma escola legitimamente inclusiva. }\end{array}$ \\
\hline 11 & $\begin{array}{lr}\text { Débora } & \text { Gomes e } \\
\text { Pedrina } & \text { Duarte } \\
\text { Ticianeli } & \end{array}$ & $\begin{array}{ll}\text { Mozart } & \text { Neves } \\
\text { Ramos } & \end{array}$ & $\begin{array}{l}\text { Aborda o desenvolvimento da educação no país e dos } \\
\text { números do IDEB }\end{array}$ \\
\hline 12 & Não informado & $\begin{array}{l}\text { Roseana } \quad \text { Pereira } \\
\text { Mendes }\end{array}$ & $\begin{array}{l}\text { Falas sobre os avanços, diretrizes e propostas do } \\
\text { Ministério da Educação em relação à primeira etapa da } \\
\text { Educação Básica no Brasil. }\end{array}$ \\
\hline 13 & Débora Gomes & Dermeval Saviani & $\begin{array}{l}\text { Busca trazer o entendimento sobre a pedagogia } \\
\text { histórico-crítica, que faz parte das diretrizes } \\
\text { metodológicas da Secretaria de Educação de Maringá. }\end{array}$ \\
\hline 14 & Não informado & $\begin{array}{ll}\text { Maria } & \text { do } \text { Pilar } \\
\text { Lacerda } & \text { Almeida e } \\
\text { Silva } & \end{array}$ & $\begin{array}{l}\text { Fala sobre a educação, seus educadores e suas } \\
\text { perspectivas. }\end{array}$ \\
\hline 15 & \begin{tabular}{llr} 
Débora & \multicolumn{2}{r}{ Gomes; } \\
Eliana & Moreira \\
Amaral de & Souza; \\
Elianara & Villa Nova \\
Macedo; & Nilda da \\
\end{tabular} & $\begin{array}{l}\text { Márcia Regina de } \\
\text { Sousa Storer }\end{array}$ & $\begin{array}{l}\text { Destaca algumas informações sobre o papel da } \\
\text { psicomotricidade no desenvolvimento da criança. }\end{array}$ \\
\hline
\end{tabular}




\begin{tabular}{|c|c|c|c|}
\hline & $\begin{array}{llr}\text { Silva } & \text { Martins } & \text { e } \\
\text { Priscila } & \text { Viviane } & \text { de } \\
\text { Souza. } & & \\
\end{array}$ & & \\
\hline 16 & Débora Gomes & $\begin{array}{l}\text { Guiomar Namo de } \\
\text { Mello }\end{array}$ & Apresenta informações sobre a educação e currículo. \\
\hline 17 & $\begin{array}{lr}\text { Débora } & \text { Gomes; } \\
\text { Maruza de } & \text { Oliveira } \\
\text { Fontes; } & \text { Gisele } \\
\text { Assumpção; } & \text { Amaral } \\
\text { de Souza. } & \end{array}$ & $\begin{array}{l}\text { Edna } \quad \text { Martins } \\
\text { Borges }\end{array}$ & $\begin{array}{l}\text { Explica com detalhes informações básica sobre o IDEB } \\
\text { no Brasil. }\end{array}$ \\
\hline 18 & $\begin{array}{l}\text { Elizabeth 1. Marchi; } \\
\text { Rosangela Brogin e } \\
\text { Rosimeire S. Plepis. }\end{array}$ & $\begin{array}{l}\text { Maria Leolina Couto } \\
\text { Cunha }\end{array}$ & $\begin{array}{l}\text { Fala sobre as principais causas de maus-tratos e de que } \\
\text { maneira deve ser o procedimento em casos identificados } \\
\text { no dia-a-dia. }\end{array}$ \\
\hline 19 & Débora Gomes & Marcos Méier & $\begin{array}{l}\text { Fala de como trabalhar em equipe tornando o trabalho } \\
\text { harmônico e democrático. }\end{array}$ \\
\hline 20 & Débora Gomes & João Luiz Gasparin & $\begin{array}{l}\text { Esclarece dúvidas em relação à pedagogia Histórico- } \\
\text { Critica, adotada como proposta teórica metodológica da } \\
\text { Rede Municipal de Ensino de Maringá, e que ainda } \\
\text { suscita indagações no cotidiano de quem dela lança a } \\
\text { mão. }\end{array}$ \\
\hline
\end{tabular}

Quadro 5 - Assuntos veiculados na seção entrevista

Fonte: Revista Maringá Ensina n ${ }^{\circ} 03$ a 20 (organização das autoras)

Notamos que algumas entrevistas são elaboradas condizentes com algum assunto educacional em circulação no momento da publicação. Neste sentido, destacamos as Revistas de número 8 (2008b) e 17 (2011a), edição em que é entrevistada a Secretária da Educação Básica (SEB), Maria do Pilar. Licenciada em História (Universidade Federal de Minas Gerais), e Especialista em Gestão de Sistemas Educacionais (Pontifícia Universidade Católica de Minas), foi presidente da União Nacional dos Dirigentes Municipais de Educação (UNDIME). E na entrevista ela fala sobre as ações e metas do governo para o Plano de Desenvolvimento da educação (PDE), a entrevista foi concedida em um período pós-implementação do ensino fundamental de nove anos, e nesse enfoque ela destaca, na entrevista, quais os objetivos que se espera com essa nova realidade:

[...] A ampliação de mais um ano de estudo deve produzir um salto na qualidade de educação, pois a inclusão de todas as crianças de seis anos promoverá a permanência na escola, o sucesso no aprendizado e o aumento da escolaridade dos alunos. (MARINGÁ, 2008b, p. 13).

Na edição 17 (2011a), a entrevistada foi Edna Martins Borges, professora de História da Rede Municipal de Belo Horizonte. Especialista em Gestão Escolar. Mestre em Administração Pública na área de Políticas Sociais e Coordenadora Geral do Ensino Fundamental da Secretaria de Educação Básica do MEC. Ela explica com detalhes informações básica sobre o IDEB no Brasil, inicia sua exposição explicando que:

[...] o índice de Desenvolvimento da Educação Básica (IDEB) é um indicador que mede a qualidade do ensino no país, ele é gerado pela combinação de duas fontes, a primeira é o rendimento e o segundo é o desempenho escolar [...] a partir da criação do IDEB calculado por escola, por rede e para o próprio país, foi possível criar metas de desenvolvimento educacional de médio prazo para cada uma dessas instâncias, com metas intermediárias de curto prazo que possibilitam visualização e acompanhamento da reforma qualitativa dos sistemas educacionais. (MARINGÁ, 2011a, p. 15). 
Essas informações são condizentes ao momento, de "[...] comemoração da Secretaria de Educação de Maringá, pelos resultados obtidos no Índice de Desenvolvimento da educação Básica (IDEB) no município, atingindo meta prevista pelo MEC para 2015" (MARINGÁ, 2011a, p.4). Os temas abordados por Maria do Pilar, implantação do ensino fundamental de nove anos; e Edna Maria Borges, IDEB - índice de desenvolvimento da educação básica - explicam-se em função das preocupações manifestas por órgãos de maior representatividade política, como o MEC - Ministério da Educação e Cultura, por exemplo.

Em outras revistas os assuntos abordados nas entrevistas estão condizentes com os temas centrais das edições. As que apresentam essa característica são as edições de número 6 (2007c), cuja pauta é o meio ambiente e a de número 12 (2009c) na qual o assunto é educação infantil. A edição de número 6 (2007c) convida a participar da seção entrevista o empresário Antonio Ermínio de Moraes, Engenheiro Metalúrgico desde 1949, pela Colorado School of Mine dos Estados Unidos, recebeu em 1989 o titulo de Doutor em Metalúrgica. Ele fala [...] o Brasil está bastante atrasado no campo educacional, "demos um grande passo ao matricular todas as crianças na escola, pois o desafio agora é mantê-las na escola e, sobretudo, fazê-las aprender". (MARINGÁ, 2007c, p. 12).

Em relação ao tema da edição, mio ambiente, Antonio Ermínio de Moraes diz que "os bens da natureza foram dados por Deus. São muito preciosos, temos de conservá-los bem” (MARINGÁ, 2007c, p.13). Este foi o único entrevistado, dentre as 17 edições estudas, que pode ser caracterizado como um homem de outro setor, em todas as outras edições as entrevistas são concedidas por pessoas que tem ligação direta com o setor educacional.

Na revista de número 12 (2009c), a carta ao leitor destaca que, "[...] o editorial foi pautado na Educação Infantil, tema que vem crescendo dentro dos debates, reflexões e políticas educacionais de nosso país" (MARINGÁ, 2009c, p.4). Para falar sobre o tema foi convidada para a entrevista Roseana Pereira Mendes que é Técnica Pedagógica da Coordenação Geral de Educação Infantil do Ministério da Educação/Secretaria de Educação Básica. Ela comenta sobre os avanços, diretrizes e propostas do Ministério da Educação em relação à primeira etapa da Educação Básica no Brasil. Ela destaca que:

[...] O ensino fundamental e educação infantil são duas etapas indivisíveis, os desafios são grandes, mas o objetivo maior é o de assegurar o direito das crianças, tanto no ensino fundamental quanto na educação infantil, a brincadeira, a aprendizagem, e ao desenvolvimento, respeitadas as suas características e especificidades. (MARINGÁ, 2009c, p. 17)

Outra característica notada nas entrevistas são as de essência formativa, com assuntos que auxiliam o professor em sua prática pedagógica, os temas abordados nas entrevistas das edições de número15 (2010c), em que a entrevistada fala sobre a psicomotricidade e de número 18 (2011b) em que a entrevista debate sobre o Bullying e a violência, tem essa intenção, podendo, portanto, ser consideradas como formação continuada. Descrevemos na sequência as duas entrevistas citadas.

Na edição de número 15 (2010c), a entrevista é concedida a Márcia Regina de Sousa Storer com graduação em Pedagogia (UEM) e Mestrado em Distúrbios do Desenvolvimento (Universidade Presbiteriana Mackenzie), ela destaca algumas informações sobre o papel da psicomotricidade no desenvolvimento da criança. "[...] Psicomotricidade, para Storer, tem como objetivo a estimulação, educação, e reeducação 
psicomotora, ela permite a vivência corporal, desenvolver as potencialidades e a criatividade." (MARINGÁ, 2010c, p. 140).

Na edição de número 18 (2011b), para falar sobre um tema presente nas instituições de ensino, Violência e Bullying, foi convidada para a entrevista a Coordenadora Nacional do Centro de Combate à Violência Infantil - (CECOVI), Maria Leolina Couto Cunha, Professora e Coordenadora Adjunta do Curso de Especialização - Metodologia de Enfrentamento da Violência contra Crianças e Adolescentes da PUC/PR Especialista em Direito Penal (Universidade de Mogi das Cruzes). Especialista no Enfrentamento da Violência Doméstica contra Crianças e Adolescente (Universidade de São Paulo - Instituto de Psicologia USP/LACRI). Especialista em Direito Aplicado (Escola da Magistratura do Paraná). Ela fala sobre as principais causas de maus-tratos e de que maneira deve ser o procedimento em casos identificados no dia-a-dia, destacamos da sua fala que:

[...] a violência contra a criança é um dos atos mais vil e cruel que o ser humano é capaz de praticar. A criança, pela peculiar condição de ser em desenvolvimento, é indefesa e frágil por natureza. Os maus-tratos (físicos, sexuais e psicológicos) destroem de forma arrasadora o que existe de mais belo em seu coração. (MARINGÁ, 2011b, p. 15).

Para o profissional da educação que está em contato direto com a criança, os temas debatidos por Márcia Regina de Souza Storer e por Maria Leolina Couto Cunha, são de relevância para sua formação. Já que as citadas por Storer são importantes no momento de elaboração de atividades para o aluno, e as informações trazidas por Cunha auxiliam para que o professor saiba como proceder quando perceber casos de violência e Bullying.

Outro critério para leitura e agrupamento das entrevistas foram conteúdos referentes à parte teórica da educação. Como é o caso das edições 13 (2010a); 16 (2010 d) e 20 (2011 d). Temos na revista número 13 (2010a), um renomado professor como entrevistado, o Educador Dr. Dermeval Saviani, Formado em Filosofia (PUC/SP) em 1966. Doutorado em Filosofia da educação pela mesma universidade em 1971 é, segundo a revista, Coordenador Geral do Grupo Nacional de Estudos e Pesquisas "História, Sociedade e Educação no Brasil" (HISTEDBR). Na entrevista ele busca trazer o entendimento sobre a Pedagogia Histórico - Crítica, que faz parte das diretrizes metodológicas da Secretaria de Educação de Maringá. E um dos pontos relevantes da entrevista, para entender a função do professor frente a essa perspectiva, destacado por ele é que:

[...] Na perspectiva histórico - crítica, o eixo da ação metodológica do professor é a prática social concreta. Como se sabe, o método de ensino proposto pela pedagogia histórico - crítica tem como ponto de partida e ponto de chegada a pratica social, o que decorre do entendimento de que o ato educativo é mediação no seio da prática social. (MARINGÁ, 2010a, p. 15)

É entrevistada na revista de número 16 (2010 d), Guiomar Namo de Mello, Pedagoga, com Especialização em Orientação Educacional, Mestre em Psicologia da Educação, Doutora em Educação e com Pós-Doutorado em Educação Comparada. Atualmente é Diretora Presidente da Escola Brasileira de Professores (EBRAP), ela apresenta no decorrer da entrevista, informações sobre currículo e fazer pedagógico na sala de aula. Para ela

[...] os quatro pilares citados no documento Delors (aprender e conhecer, aprender a fazer, aprender a ser e aprender a conviver), que fundamenta a 
prática pedagógica, devem ser traduzido nos elementos que constituem o processo educativo na escola, para que possam nortear as políticas públicas. (MARINGÁ, 2010 d, p. 14)

Ela destaca que "[...] o currículo pode perfeitamente facilitar os projetos interdisciplinares, o ensino por projetos no qual, a equipe da escola toda participa" (MARINGÁ, 2010 d, p.15). Nesse sentido ela ressalta que os conteúdos devem ser desenvolvidos de forma interdisciplinar, mas para tanto é preciso preparar os professores e gestores e é preciso criar condições para que o trabalho coletivo seja realmente construtivo. E, além disso, para ela os professores devem ter domínio dos conteúdos, para realizar um bom trabalho.

João Luiz Gasparin possui graduação em Filosofia (Universidade Regional do Noroeste do Estado do Rio Grande do Sul), graduação em Letras Português / Inglês (Faculdade de Filosofia Ciências e Letras de Paranavaí), Especializado em Métodos e Técnicas do Ensino (Universidade de Brasília), Mestrado em Educação (Pontifícia Universidade Católica do Rio Grande do Sul) e Doutorado em Educação: História e Filosofia da Educação (Pontifícia Universidade Católica de São Paulo). Autor do livro "Uma didática para a pedagogia Histórico - Crítica." Concede entrevista para a revista Maringá ensina na $20^{\circ}$ edição $(2011$ d). Ele esclarece dúvidas em relação à pedagogia Histórico - Critica, adotada como proposta teórica metodológica da Rede Municipal de Ensino de Maringá, e que segundo a Revista "[...] ainda suscita indagações no cotidiano de quem dela lança a mão.” (MARINGÁ, 2011 d, p. 16), no decorrer da entrevista ele esclarece que:

[...] A pedagogia Histórico - Critica, se constitui em um caminho amplo, mas direcionado para que o professor alcance seus objetivos ao desenvolver suas atividades no cotidiano escolar. Dessa maneira ao adotar a Pedagogia Histórico-Critica, o professor tem a possibilidade por meio do "processo dialético dessa nova pedagogia" de incorporar e superar "os processos anteriores de ensino e aprendizagem". Para isso destaca que é fundamental que o professor a conheça e seja capaz de transformá-la em ações que realizem o ciclo prática-teoria-prática. Destaca-se ainda que ao adotar os cinco passos da Pedagogia HistóricoCritica o professor deve ter clareza que se o educando partiu da realidade empírica que lhe era familiar, deve retornar a mesma realidade, mas com outro olhar mais elevado e cientifico para inserir-se nela como um cidadão que busca transformar de alguma forma o ambiente que vive. (MARINGÁ, 2011 d, p. 16)

Como já destacamos as entrevistas com o professor Dermeval Saviani; Guiomar Namo de Mello e João Luiz Gasparin apresentam informações que vão ao encontro com a prática pedagógica do professor proporcionando bases teóricas, ou seja, observando as entrevistas percebemos que uma vem como complemento para a outra, todas tratam de assuntos sobre currículos, porém os entrevistados dão forma às entrevistas, acrescentando informações e esclarecimentos que são pertinentes às práticas pedagógicas.

Nas entrevistas das edições de números 3 (2006); 4 (2007a); 5 (2007b); 9 (2008c); 10(2009a); 11(2009b) e 14(2010b) notamos como singularidade as falas dos entrevistados, nestas são direcionadas à educação no Brasil e os educadores. Os temas diferem entre si, porém as respostas das perguntas às aproximam como poderemos notar nos excertos selecionados e expostos. 
Na revista de número 03 (2006) o entrevistado foi Içami Tiba, escritor, Especialista em Educação e Médico psiquiatra há 37 anos, e de acordo com a revista "[...] está entre os educadores mais requisitados do país" (MARINGÁ, 2006). A revista concede a ele o espaço para falar da educação escolar e familiar, onde ele aponta os erros cometidos pelos pais ao criarem seus filhos, e como sanar essas dificuldades. Ao ser questionado sobre a educação no Brasil ele destaca que:

[...] A educação escolar, tampouco familiar prepara os jovens para o mercado de trabalho, para a cidadania. Mesmo sem mudar o currículo psicopedagógico que está bastante desatualizado para as necessidades de hoje, muitos procedimentos podem ser adotados, para explorar ao máximo o que se pode ser feito. Baixos salários não deveriam desmotivar os educadores, pois o que eles fazem não tem medida financeira, ser educador é dignidade que não se vende. (MARINGÁ, 2006, p.11)

Gabriel Chalita foi entrevistado na revista de número 04 (2007a), Doutor em Comunicação e Semiótica (PUC de São Paulo), Doutor em Direito (PUC de São Paulo); Mestre em Direito e Mestre em Ciências Sociais (pela mesma universidade); Bacharel em Direito e Filosofia. E segundo a revista, entre as atividades políticas que desenvolveu está o cargo de Secretário da Educação do Estado de São Paulo. Na entrevista, ele relata alguns pontos para a melhoria da educação no país, notamos que as perguntas levam a pensar na atuação do educador na sala de aula, reafirmando o papel e responsabilidade deste. Para ele,

[...] são necessárias algumas iniciativas para avançarmos em relação à educação com qualidade no nosso país. Primeiramente, é fundamental valorizar o professor porque ele é a alma e o pilar da educação, com o professor motivado e reconhecido, todo processo fica mais fácil. [...] Professor é aquela pessoa que lapida diamantes. (MARINGÁ, 2007a, p. 11).

Na Revista Maringá Ensina número 5, a entrevista é concedida por Viviane Senna, graduada em Psicologia (Pontifícia Universidade Católica de São Paulo), com Especialização em Psicologia Junguiana (Instituto Sedes Sapientiaes da Universidade Católica), ela fala sobre a importância do investimento na educação da criança e do adolescente, e comenta sobre os programas educacionais desenvolvidos pelo Instituto Ayrton Senna. Ao final entrevista, ela destaca que:

[...] O professor brasileiro, especialmente o da escola pública, tem sido desprestigiado há décadas. Une-se a baixa remuneração e a falta de espaços para a capacitação. $\mathrm{O}$ que o professor precisa é de apoio pedagógico e motivacional. [...] Melhores salários são fundamentais, mas um gerenciamento mais efetivo da educação, que tenha como meta o sucesso do aluno e a capacitações sistemáticas são ferramentas eficientes que impulsionam o profissional e o ajudam a melhorar seu desempenho e sua autoconfiança. (MARINGÁ, 2007b, p.11)

Na continuidade destacamos a fala de Gabriel Perissé, Doutor em Filosofia da Educação (USP), Mestre em Literatura Brasileira (USP), e Bacharel em Letras (Faculdade Letras da Universidade Federal do Rio de Janeiro-1985). Entrevistado na revista de número 9 (2008c), ele comenta sobre a responsabilidade do educador no processo de ensino aprendizagem, ele destaca a importância dos professores incentivarem o hábito de 
leitura dentro e fora do contexto escolar. E no que diz respeito aos professores ele ressalta que:

[...] os erros de um (a) professor (a) tem consequiências talvez menos visíveis, num primeiro momento, mas muito mais graves a longo prazo [...] as falhas de hoje são fruto dos nossos erros no passado. Daí, a necessidade de oferecermos aos candidatos a docência uma formação inicial melhor e acompanhá-los ao longo de sua vida profissional. Professores profissionalmente valorizados tornam-se mais conscientes de sua responsabilidade. (MARINGÁ, 2008c, p. 13).

O entrevistado na revista de número 10 (2009a) foi José Pacheco, Especialista em Música e em Leitura e Escrita, Mestre em Ciências da Educação (Universidade do Porto), é também coordenador da Escola da Ponte, da qual é idealizador desde 1976. Ele fala sobre a educação brasileira, sobre o papel do educador e sobre os processos de aprendizagem na construção de uma escola legitimamente inclusiva. Segundo ele "[...] a escola brasileira tem os professores certos trabalhando de modo errado. O professor brasileiro precisa recuperar a autoestima e beneficiar da hetero-estima". (MARINGÁ, 2009a, p. 17).

Na revista de número 11 (2009b), o entrevistado foi Mozart Neves Ramos, Doutor em Química, (UNICAMP) com Pós-Doutorado em Química (Politécnica de Milão). Pesquisador nível 1 do CNPq. Foi reitor da Universidade Federal de Pernambuco em dois períodos (1996-1999 e 2000 -2003). É, de acordo com a revista membro do Conselho Nacional de Educação, Vice-Presidente da Câmara de Educação Básica e PresidenteExecutivo do Movimento Todos Pela Educação. Na entrevista, ele informa como funciona o IDEB e sobre os números do IDEB, e destaca que:

[...] O IDEB é uma fotografia que procura retratar um filme de forma resumida e objetiva. Ele deve ser usado assim em consonância com outros valores intrínsecos a avaliação na direção da tão desejada qualidade. O IDEB é importante para o grande publico, mas para as redes e para as escolas é importante incorporar outros valores, como a própria auto avaliação, levando em consideração outros indicadores de aprendizagem, por exemplo, a avaliação do docente pelo discente (MARINGÁ, 2009b, p. 15).

Quando questionado sobre a melhoria que deve haver na educação, ele aponta que:

[...] A valorização do professor e do profissional da gestão escolar são questões centrais para a melhoria da qualidade do ensino público [...] e a educação de qualidade para todos é o único vetor capaz de alinhar o desenvolvimento econômico com o social [...] mais recursos são importantes associados à profissionalização da gestão. (MARINGÁ, 2009b, p. 15).

Na edição de número 14 (2010b), a entrevistada foi Secretária da Educação Básica (SEB) Maria do Pilar Lacerda Almeida e Silva. Nesta ela fala sobre a educação, seus educadores e suas perspectivas. Destaca que o educador deve ter uma formação continuada que valorize o aprofundamento prático-teórico, para fazer diferença na sala de aula, e com relação à escola ela destaca que:

[...] são crianças do século XXI freqüentando uma escola que ainda tem o pensamento e a cultura do século passado. A escola básica contemporânea que inclui, acolhe desperta para o conhecimento, provoca 
a reflexão, aprofunda conceitos, não pode ser mais uma escola para transmitir informações, mas para tratar as informações. Uma escola contemporânea deve pensar o tempo escolar de maneira flexível, deve se articular com a comunidade e os equipamentos públicos ou privados que a cercam, e mais do que isto, a escola precisa ser sempre o local do conhecimento e não se aprofunda o conhecimento sem curiosidades. (MARINGÁ, 2010b, p. 12)

Observamos, portanto, que as entrevistas com Içami Tiba; Gabriel Chalita; Viviane Senna; Gabriel Perissé; José Pacheco; Mozart Neves Ramos e Maria do Pilar Lacerda levam a reflexão sobre a educação brasileira. O desprestígio do professor é apontado em algumas, sendo sugerido que, a "valorização" deste é um passo em relação à melhoria da educação brasileira. Em outros pontos notamos que, o curso superior de formação é questionado, sendo, portanto, sugerido que a formação inicial do professor deve ser de melhor qualidade, e que este quando atuante como profissional da educação deve estar sempre em formação continuada.

Para finalizar a descrição das entrevistas, identificamos duas que diferem em conteúdos com as demais descritas. A primeira, que queremos destacar é a publicada na edição de número 7 (2008a), nesta o espaço foi reservado para informações sobre o Programa Educacional de Resistência às Drogas e à Violência (PROERD) com a TenenteCoronel Rita Aparecida de Oliveira, que comanda o programa no Estado do Paraná, destacado pela Revista como "um dos projetos mais importantes aplicados na área da educação e comportamento de crianças e adolescentes" (MARINGÁ, n.2008a, p. 4). Na entrevista ela fala sobre o PROERD e a importância da abertura das escolas a esse programa. Ressalta também, a importância da ligação entre família e escola para atingir um nível de formação preventiva satisfatória, no que diz respeito às drogas; e também garantir a educação e a boa formação do jovem na sociedade. Ela encerra a entrevista destacando que: "a família é o esteio da construção e realização de nossos sonhos. A escola é o sustentáculo da realização desses sonhos". (MARINGÁ, 2008a, p. 17)

A segunda, que destacamos é a publicada na edição de número 19 (2011c), com Marcos Méier, Professor de Matemática (Universidade Federal do Paraná); Psicólogo (Universidade Tuiuti do Paraná); Especialista em Educação Matemática (UNESP-Rio Claro); e Mestre em Educação (Universidade Federal do Paraná). Pesquisador e divulgador da Teoria da Modificabilidade Estrutural Cognitiva de Reven Feuerstein (Teoria da Mediação da Aprendizagem), Na entrevista, ele fala de como trabalhar em equipe tornando o trabalho harmônico e democrático, para ele:

[...] elogios na hora certa e de maneira correta podem minimizar conflitos diários, fazendo com que as pessoas ao mesmo tempo em que tomem ciência de suas dificuldades e fragilidade, sintam-se motivadas a continuar se empenhando em suas ações. Com isto, os maiores beneficiados serão os alunos que terão acesso à aprendizagem significativa. (MARINGÁ, 2011c, p. 14)

Observamos na referida entrevista que esta se direciona a outro publico, o gestor. Em todas as entrevistas que faz parte de nosso estudo, percebemos que está é a única que se volta especificamente, para o dirigente das unidades escolares. Concordamos, contudo, que algumas pelo caráter informativo que tem, engloba o gestor escolar.

Ao final da descrição da seção entrevista, ressaltamos que a imprensa pedagógica, como qualquer outro impresso, não é neutra, uma vez que transmite interesses e 
concepções de determinados grupos sociais, com objetivo de que sua mensagem seja incorporada.

\section{Considerações Finais}

Chartier (2002a) explicita que há dois entendimentos para pensar a construção das Identidades Sociais. Uma é entendida pelas relações de forças entre as representações impostas por quem detém o poder de classificar, nomear e a definição submetida ou resistente que cada um produz de si. A outra considera a formação do grupo como a tradução de crédito concedido, assim o reconhecimento da sua existência se dá por meio da exibição de uma identidade. Com base nesse entendimento sobre como se dá o processo de formação da identidade para ter o exercício da representação, é que apresentamos discussão sobre o que pudemos observar os diversos números da Revista Maringá Ensina.

Chartier (1996) alerta-nos que o autor de um texto, ou grupo que ele representa, pretende passar ao leitor a compreensão do assunto de acordo com o seu desejo ou entendimento. Quer dizer, ao escrever um texto, pensa-se na forma como o leitor interpreta e lê, já que o esforço é para que o entendimento do texto esteja em consonância com a sua intenção. Esta prática configura-se como instruções conscientes ou inconscientes "incutidas" no leitor pelo texto. Sendo assim, o autor expressa-se com uma intencionalidade específica, ligada a seus interesses pessoais e ou de um grupo.

O leitor tem possibilidade de autonomia em sua interpretação e ou apropriação pela leitura, o que fizemos aqui, à luz do entendimento de Chartier (1990, 1996, 2002a) e Certeau (1982, 1994), foi demonstrar as formas estratégicas usadas na escrita de um material impresso. A construção se faz numa "luta" constante ao pretender estabelecer o entendimento coerente ao autor e ao seu grupo, esperando refleti-lo em suas ações cotidianas, resultando, dessa maneira em uma nova apropriação.

Entretanto, cada tipo de texto tem características próprias, com uma ordem para seu discurso, dependendo de qual recurso impresso fará uso. Chartier (2002a) menciona que a cultura impressa, como a conhecemos, estabelece-se por diferentes objetos, como: livros, diários, revistas, jornais, cartas, documentos, etc. Uma vez que são categorias de textos produzidos de maneiras diferentes, porque cada uma destina-se a um público leitor diferenciado. Para estes objetos diferenciados, devem-se levar em consideração as peculiaridades e objetivos essenciais específicos para a sua produção, o autor escolhe o recurso impresso que melhor possa atender ao conteúdo e discurso a ser utilizado.

Diante dessas considerações, podemos inferir que a revista foi a forma de comunicação escrita escolhida entre representantes e representados, evidencia-se ainda, uma estratégia do grupo representante, tendo em vista as possibilidades oferecidas por esse recurso impresso na sua materialidade e organicidade. Em outras palavras, o "simples" fato de a escolha do objeto de comunicação entre representantes e representados ser uma revista indica uma intencionalidade. Sabemos que o mesmo tem algumas características que lhes são próprias e que podem ter contribuído na sua escolha como recurso de comunicação entre os educadores da Rede Municipal de Ensino.

Esclarece Chartier (1996, p.97) que o estudo dos impressos deve ser feito cuidadosamente, haja vista que, em sua apresentação e ou aparência "material", há muitos detalhes a serem observados e considerados. O primeiro deles, na tentativa de melhor esclarecê-lo, é a sua materialidade e, em seguida, a organicidade do material escrito. Chartier (1996, p.97) assevera: “[...] porque examina um material em que a organização 
tipográfica traduz, claramente, uma intenção editorial e porque pode revelar a marca, no próprio objeto, das maneiras populares de ler".

A materialidade da fonte diferencia-se em seus discursos, visto que cada um tem, historicamente, a direção que o discurso deve tomar, usando o conhecimento e ou a percepção das características de cada modalidade de impresso. Complementa esse sentido Chartier (1996) quando menciona que, ao escolher o objeto impresso que irá fazer uso, deve-se levar em consideração a estrutura material, característica discursiva e de público de maior pertinência a quem se pretende publicar. Desse modo, a intencionalidade de levar o texto a uma apropriação desejada é feita desde o primeiro momento, na escolha do objeto que irá veicular suas ideias.

Os textos impressos, utilizados para o estudo da história, como menciona Chartier (2002b), são os mesmos para todos os que dele fazem uso, independente de classe social, cultural, religiosa e situação econômica. Todavia a diferença se faz presente na forma como cada leitor vai estabelecer entendimento sobre o que está escrito no impresso e o diálogo que estabelecerá com o seu vivido, com a sua realidade e na forma como pode ou não incorporar sobre o que leu no seu cotidiano. Em suma, o texto pode ter significado diferenciado a cada leitor, quer dizer, cada leitor ou grupo pode apropriar-se do conteúdo do texto de forma diferenciada. Tendo isso em vista, explica-se a preocupação com a Identidade Social a ser formada no grupo para que objetivos, metas e outros sejam aproximados, buscando facilitar a apropriação de todos pelos conteúdos elencados e escritos, levando ao convencimento e à aceitação do grupo a representação. A passagem abaixo define, em contornos gerais, o conceito de apropriação:

A apropriação tal como entendemos visa uma história social dos usos e das interpretações, relacionados às suas determinações fundamentais e inscritos nas práticas específicas que os produzem. Dar assim atenção às condições e aos processos que, muito concretamente, sustentam as operações de construção do sentido (na relação de leitura e também em muitas outras) é reconhecer, contra a antiga história intelectual, que nem as inteligências nem as idéias são desencarnadas e, contra os pensamentos do universal, que as categorias dadas como invariantes, quer sejam filosóficas ou fenomenológicas, devem ser construídas nas descontinuidades das trajetórias históricas (CHARTIER, 1990, p.26-27).

O objetivo da Apropriação é construir o que poderíamos entender como uma história social das interpretações, remetidas para suas determinações fundamentais, que são o social, o institucional e o cultural. Chartier (1990), "dialogando" com Certeau (1994) designa a apropriação como tensão principal ao permear a representação, porque, ao apropriar-se das ideias e propostas, a representação faz-se acontecer.

Ao finalizar as considerações constatamos que ampliamos nossa compreensão sobre a Revista Maringá Ensina, pois para podermos trabalhar com a temática escolhida precisamos recorrer inúmeras vezes, a inteireza do impresso, a fim de melhor compreender os objetivos propostos, ao abordar cada temática, podemos, agora, lançar a ela outro olhar, pois a entendemos como capaz de revelar elementos que interferem na construção do fazer pedagógico. A Revista Maringá Ensina, como exemplo de Imprensa Pedagógica, propiciou-nos conhecer as ideias pedagógicas e educacionais que circularam ou circulam na cidade. Sendo, portanto uma estratégia utilizada pela Secretaria de Educação do Município, na formação continuada dos profissionais de educação. 


\section{Referências}

BASTOS, Maria Helena Câmara. As revistas pedagógicas e a Atualização do professor: a revista do ensino do Rio Grande do Sul (1951-1992) In: CATANI, Denice Bárbara; BASTOS, Maria Helena Câmara (Org.). Educação em Revista: a imprensa periódica e a história da educação. São Paulo: Escrituras, 1997. p.47-75.

BICCAS, Maurilane de Souza. O impresso como estratégia de formação: Revista do Ensino de Minas Gerais (1925 - 1940). Belo Horizonte: Argumentum, 2008.

BLOCH, Marc. Apologia a história ou o oficio do historiador. Rio de Janeiro: Jorge Zahar. Ed., 2001

BRASIL, Lei n ${ }^{\circ}$ 9.394, de 20.12.96, Estabelece as Diretrizes e Bases da Educação Nacional.

CAPELATO, Maria Helena R. História da Imprensa no Brasil. São Paulo: Contexto, 1988.

CERTEAU, Michel de. A escrita da história. Tradução de Maria de Lourdes Menezes; Revisão Técnica [de] Arno Vogel. Rio de Janeiro: Forense Universitária, 2006.

CHARTIER, Roger. A beira da falésia: a história entre incertezas e inquietude. Tradução de Patrícia Chittoni Ramos. Porto Alegre: Ed. Universidade/UFRGS, 2002.

CHARTIER, Roger. A história cultural: entre práticas e representações. Tradução de Maria Manuela Galhardo. Lisboa: Difel, 1990.

CHARTIER, Roger. O mundo como representação. Estud. av., Abr 1991, vol.5, no.11, p.173191. ISSN 0103-4014 - www.scielo.br

CHARTIER, Roger. Os desafios da escrita. Tradução de Fúlvia M. L. Moretto. São Paulo: Ed. UNESP, 2002a.

CHARTIER, Roger. Práticas de leitura. Tradução de Cristiane Nascimento; Revisão da Tradução Angel Bojadsen. São Paulo: Estação Liberdade, 1996.

LE GOFF, Jacques. Documento/monumento. IN: LE GOFF, Jacques. História e Memória. Campinas: Editora da UNICAMP, 2003 - p. 525 - 541

LOPES, Eliane Marta Teixeira; GALVÃO, Ana Maria de Oliveira. História da educação. Rio de Janeiro: DP\&A, 2001.

MARINGÁ. Revista Maringá ensina. SEDUC, abr./maio/jun. 2008b, n.8.

MARINGÁ. Revista Maringá ensina. SEDUC, ago./set./out. 2006, n.3.

MARINGÁ. Revista Maringá ensina. SEDUC, ago./set./out. 2008c, n.9.

MARINGÁ. Revista Maringá ensina. SEDUC, ago./set./out. 2010d, n.16.

MARINGÁ. Revista Maringá ensina. SEDUC, ago./set./out. 2011d, n.20.

MARINGÁ. Revista Maringá ensina. SEDUC, fev./mar./abr. 2007b, n.5.

MARINGÁ. Revista Maringá ensina. SEDUC, fev./mar./abr. 2009a, n.10.

MARINGÁ. Revista Maringá ensina. SEDUC, fev./mar./abr. 2010b, n.14.

MARINGÁ. Revista Maringá ensina. SEDUC, fev./mar.abr. 2011b, n.18.

MARINGÁ. Revista Maringá ensina. SEDUC, jul./ago./set. 2009c, n.12.

MARINGÁ. Revista Maringá ensina. SEDUC, maio/jun./jul. 2007c, n.6.

MARINGÁ. Revista Maringá ensina. SEDUC, maio/jun./jul. 2009b, n.11.

MARINGÁ. Revista Maringá ensina. SEDUC, maio/jun./jul. 2010c, n.15.

MARINGÁ. Revista Maringá ensina. SEDUC, maio/jun./jul. 2011c, n.19. 
MARINGÁ. Revista Maringá ensina. SEDUC, nov./dez. 2006, jan.2007a, n.4.

MARINGÁ. Revista Maringá ensina. SEDUC, nov./dez. 2007, jan.2008a, n.7.

MARINGÁ. Revista Maringá ensina. SEDUC, nov./dez. 2009, jan.2010a, n.13.

MARINGÁ. Revista Maringá ensina. SEDUC, nov./dez./ 2010, jan. 2011a, n.17.

MARTINEZ, Edilene Cunha. A Imprensa Pedagógica como tema e objeto para a História da Educação Paranaense: Jornal Escola Aberta (1986-1988). 2009. 172f. Dissertação (Mestrado em Educação) - Universidade Estadual de Maringá. Orientadora: Prof ${ }^{\mathrm{a}}$. $\mathrm{Dr}^{\mathrm{a}}$. Elaine Rodrigues.

NÓVOA, António. A imprensa de educação e de ensino: concepção e organização do repertório português. In: CATANI; Denice Bárbara; NUNES, Clarice; CARVALHO, Marta Maria. Historiografia da educação e fontes. Cadernos ANPED, Porto Alegre, n.5, p.7-64, set., 1993.

NÓVOA, António. A imprensa de educação e de ensino: concepção e organização do repertório português. In: CATANI; Denice Bárbara; BASTOS, Maria Helena Câmara. (Org.). Educação em Revista: a imprensa periódica e a história da educação. São Paulo: Escrituras, 1997. p.11-31.

OLIVEIRA, Wanessa Gorri de Oliveira. A imprensa pedagógica como fonte e objeto para uma escrita da história: em destaque a prática pedagógica sugerida ao professor de educação infantil pela revista criança (1996-2006). 2011. 199f. Dissertação (Mestrado em História e Historiografia da Educação) - Universidade Estadual de Maringá. Orientadora: Prof ${ }^{a}$. Dr ${ }^{a}$. Fátima Maria Neves.

RODRIGUES, Elaine. A imprensa pedagógica como fonte, tema e objeto para a história da educação. In: COSTA, Célio Juvenal; MELO, José Joaquim Pereira; FABIANO, Luiz Hermenegildo (Orgs.). Fontes e métodos em história da educação. Dourados, MS: Ed. UFGD, 2010. p.311-325.

SODRÉ, N. Werneck. História da Imprensa no Brasil. 4.ed. Rio de Janeiro: Mauad. 1966.

Notas

\footnotetext{
${ }^{1}$ Publicou as seguintes obras - Três fases da imprensa brasileira - Proença, 1960. Jornal, história e técnica Rio de Janeiro - MEC, 1964. Por último destaco: Jornalismo, informação e comunicação - Martins, 1971.

${ }^{2}$ Caiobá/PR; Campo Mourão/PR; Ortigueira/PR; Terra Boa/PR; Sarandi/PR.

${ }^{3}$ As informações expostas a seguir foram retiradas do site: www.jornalmateriaprima.com.br, acesso em 23/11/2011.

${ }^{4}$ De acordo com a LDB 9.394/1996, Art. 18. Os sistemas municipais de ensino compreendem:

I - as instituições do ensino fundamental, médio e de educação infantil mantidas pelo Poder Público municipal;

II - as instituições de educação infantil, criadas e mantidas pela iniciativa privada;

III - os órgãos municipais de educação.
}

Recebido em novembro/2012

Aprovado em dezembro/2012 